transformed tension profile, ultimate strength of beams, vebe test, vibration, wire, and Young's Modulus. This $A B C$ is a most useful contribution to the literature of prestressed concrete and will be found to be of great practical value to all concerned with the use of normally reinforced concrete as a structural material. While assuming that the reader possesses a basic knowledge of the theory of prestressing, the explanations under each heading are clear and concise. It is pointed out that working efficiency of any prestressed member is dependent on a number of variables the quantitative assessment of which is often necessary by the structural engineer. In this connexion numerical values given to these factors in this booklet are based on the British Standards Code of Practice CP 115: 1959, The Structural Use of Prestressed Concrete in Buildings. References are made to experimental results obtained at the Research Station of the Cement and Concrete Association, and footnotes direct the reader to relevant British Standards and other works on this important subject.

\section{The Ciba Journal}

The Ciba Journal for Autumn 1962 (No. 23) includes a note on demonstrations of advances in photochemistry shown in colour on the 'Eidophor' screen at Zurich last summer, Dr. K. Hofmann's remarks on molecular medicine delivered at the dedication last May of Ciba Summit's Development Research Centre, and some account of the Goregaon Centre for fundamental biological chemical research, near Bombay, to be completed next spring. The new institute will co-operate fully with university and Government research institutions in India and other parts of Asia. There is a note outlining the differences in structure and behaviour between 'Doriden' (or glutethimide) and thalidomide, and an account of the scope and activities of the Summit Scientific Information Centre, in which Dr. F. Knill stresses the need to limit mechanization to the purposes which justify its expense and effort: the human factor is still important. Among shorter articles there is a description of the Snowy Mountains hydroelectric and irrigation scheme.

\section{Bibliography of Gas-Liquid and Liquid-Liquid interfaces}

THE Research Department of Joseph Crosfield, Ltd., have made a handsome present to the scientific world with their new bibliography of published work on gas-liquid and liquid-liquid interfaces. The compiler is Dr. D. W. Stephens, and he has done a very thorough job: there are more than 2,600 references. The topics covered include some in which solid surfaces are involved also, a large number of papers on contact angles being cited. The work since 1890 is very thoroughly dealt with, and very little seems to have been missed; some references have dates as recent as 1961. Rayleigh's classical work is noted; but perhaps wisely, since the bibliography is intended for present-day research workers, the early history is lacking; there is no mention of Thomas Young, Laplace or Dupré, and Clerk Maxwell's comprehensive article "On Capillarity", in pre-1914 editions of the Encyclopcedia Britannica, is not mentioned. This is a pity, since it contains an admirable summary of the very early work, even back to Leonardo da Vinci. But one cannot have everything, and this bibliography is so comprehensive that it will save research workers and writers of books untold hours of searching in the literature. In an introduction, Prof. J. T. Davies directs attention to the alarming and self-defeating increase in the rate of publication of papers. One example may be quoted: more than 100 communications on the effect of surface films on the rate of evaporation of water, a subject which assumed technical importance only a few years ago, are cited. But bibliographies such as this, easy to use and concise, arranged under both authors and subjects, do help to overcome this ever-increasing plague which now bosets scientific literature, in a most helpful way. The publishers' address is: Joseph Crosfield and Sons, Ltd., Bank Quay, Warrington, Lancashire.

\section{Genesis of Volcanic Pipes by Fluidization}

IN 1961 the Russian geologists, V. I. Mikheyenko and N. I. Nenashev, published a remarkable demonstration that the diamond-bearing pipes of Yakutia were intruded as a relatively cold, gas-charged mush of solid-rock fragments, and not, as hitherto supposed, prodominantly in a water-enriched magmatic state. An English translation of this report has recently appeared (International Geology Review, 4, 916; 1962). Although these diamantiferous pipes and dykes were emplaced in late Mesozoic times, the absolute age of the kimberlites of which they are formed, established by potassium : argon ratios on the component phlogopite mica, is not less than 660 million years. In other words, the formations wore not molten within 500 million years of the time of their intrusion, but were emplaced from depth as a cold, fluidized, aqueous slurry which in its ascent disrupted from the country-rocks the many types of xenolith which the pipes contain. These observations, coupled with the recent Russian discovery of diamonds in a xenolith of plagioclase-bearing eclogite-like rock of crustal type, may materially affect geological thinking on the origin of diamonds and on the deeper structure of the continental crust. Contemporaneously, emphasis has been placed on the importance of fluidization or 'gas-tuff streaming' in a series of recent papers by Dr. E. H. Francis on the Carboniferous volcanic vents in the Midland Valley of Scotland, the latest of which is on "Volcanic Neck Emplacement and Subsidence Structures at Dunbar, South-East Scotland" (Trans. Roy. Soc. Edin., 65, No. 2. Pp. 41-58+2 plates. Edinburgh: Royal Society of Edinburgh, 1962. 8s. 6d.). Sixty years ago, Sir Archibald Geikie drew comparisons between the Scottish necks and the diamond pipes of South Africa. The former have never yielded a diamond; but it is nevertheless of interest to find genetic conclusions drawn from field observations in Scotland so closely paralleled by the results of geochronological research on the diamantiferous diatremes of Siberia.

\section{Pinus radiata}

Pinus radiata, although a tree of little importance in its native habitat of southern California, has established itself as a most important exotic, particularly in the southern hemisphere. Wherever climate and soils are suitable, it has given outstanding results. It occupies a very prominent position in New Zealand forestry, supplying about half the total cut of homegrown timber. In addition to lumber, it is the sole raw material used in the Now Zealand pulp industry. Thus, besides home consumption, this exotic is also providing produce for export. The successes achieved are all the more remarkable because the radiata stands are only 40 years old or less. Similar results, 